\title{
Patient out-of-pocket spending in cranial neurosurgery: single-institution analysis of 6569 consecutive cases and literature review
}

\author{
*Seungwon Yoon, BS, Michael A. Mooney, MD, Michael A. Bohl, MD, John P. Sheehy, MD, \\ Peter Nakaji, MD, Andrew S. Little, MD, and Michael T. Lawton, MD \\ Department of Neurological Surgery, Barrow Neurological Institute, Phoenix, Arizona
}

\begin{abstract}
OBJECTIVE With drastic changes to the health insurance market, patient cost sharing has significantly increased in recent years. However, the patient financial burden, or out-of-pocket (OOP) costs, for surgical procedures is poorly understood. The goal of this study was to analyze patient OOP spending in cranial neurosurgery and identify drivers of OOP spending growth.
\end{abstract}

METHODS For 6569 consecutive patients who underwent cranial neurosurgery from 2013 to 2016 at the authors' institution, the authors created univariate and multivariate mixed-effects models to investigate the effect of patient demographic and clinical factors on patient OOP spending. The authors examined OOP payments stratified into 10 subsets of case categories and created a generalized linear model to study the growth of OOP spending over time.

RESULTS In the multivariate model, case categories (craniotomy for pain, tumor, and vascular lesions), commercial insurance, and out-of-network plans were significant predictors of higher OOP payments for patients (all $p<0.05$ ). Patient spending varied substantially across procedure types, with patients undergoing craniotomy for pain $(\$ 1151 \pm \$ 209)$ having the highest mean OOP payments. On average, commercially insured patients spent nearly twice as much in OOP payments as the overall population. From 2013 to 2016, the mean patient OOP spending increased 17\%, from $\$ 598$ to $\$ 698$ per patient encounter. Commercially insured patients experienced more significant growth in OOP spending, with a cumulative rate of growth of $42 \%$ ( $\$ 991$ in 2013 to $\$ 1403$ in 2016).

CONCLUSIONS Even after controlling for inflation, case-mix differences, and partial fiscal periods, OOP spending for cranial neurosurgery patients significantly increased from 2013 to 2016 . The mean OOP spending for commercially insured neurosurgical patients exceeded $\$ 1400$ in 2016 , with an average annual growth rate of $13 \%$. As patient cost sharing in health insurance plans becomes more prevalent, patients and providers must consider the potential financial burden for patients receiving specialized neurosurgical care.

https://thejns.org/doi/abs/10.3171/2018.1.FOCUS17782

KEYWORDS cost transparency; cost sharing; out-of-pocket costs; patient payments; health care economics

$\mathrm{H}$ EALTH care spending in the United States is the highest in the world and continues to rise at a pace that exceeds total economic growth..$^{15}$ In this evolving health care environment, patient out-of-pocket (OOP) costs totaled $\$ 352.5$ billion dollars in 2016, representing $11 \%$ of total US health care spending. ${ }^{5}$ Additionally, total patient OOP spending grew nearly $4 \%$ in 2016, the fastest rate of growth since 2007 and twice the average annual growth rate of the previous decade. OOP spending is projected to grow to $\$ 542.3$ billion by 2025 due to increasing costs of health care delivery and the changing infrastructure of insurance plans. ${ }^{12}$

The high cost of health care continues to be a persistent concern among the general public. ${ }^{7}$ According to a report from the Kaiser Family Foundation, 1 in every 4 adults, including those with private or employer-sponsored insurance, struggles to pay for medical bills. ${ }^{9}$ In fact, medical debt is consistently cited as one of the leading causes of bankruptcies in the US. ${ }^{11}$ Surgical specialties, including neurosurgery, represent a unique subset of care delivery,

* S.Y. and M.A.M. contributed equally to this work. 
as operative cases can be highly complex and expensive, requiring multidisciplinary teams of surgeons and/or multiple stages of surgery. Unfortunately, there are minimal data available regarding patient OOP costs associated with surgical care, and patients and providers often commit to an operative intervention without knowing the potential financial burden it may impose for a patient.

In an effort to improve cost transparency in neurosurgery, we sought to examine patient OOP spending associated with cranial neurosurgical procedures performed at our institution from a comprehensive payer mix. We examine the drivers of OOP spending at our institution, as well as changes in patient OOP spending over time, in order to provide an analysis of patients' financial contributions to neurosurgical care. To our knowledge, this represents the most comprehensive analysis of patient OOP spending in the neurosurgical literature to date.

\section{Methods}

This study was approved by our institutional review board and conducted in compliance with Health Insurance Portability and Accountability Act (HIPAA) regulations. All patients who underwent a cranial neurosurgical operation at our institution (Barrow Neurological Institute, St. Joseph's Hospital and Medical Center, Phoenix, AZ) between July 2013 and May 2016 were included in the study. We retrospectively collected the following patient demographic and clinical data from our hospital electronic medical records system (PowerChart, Cerner Corp.): age, sex, date of surgery, surgeon, length of surgery, American Society of Anesthesiologists Physical Status class (assigned by the anesthesiologist at the beginning of the procedure), elective case status, length of stay, severity of illness (SOI), and procedure details. Cases were classified into subsets based on general case characteristics and operative complexity.

Details of patients' individual health coverage, such as primary payer information and in- or out-of-network status, were obtained from our hospital administrative database (Invision, Attachmate Corp.). Insurance plans were classified as commercial, Medicaid, Medicare, others (e.g., Tricare, workers' compensation, charity), and self-pay. All accounts had more than 1 year of payment eligibility at the time of data extraction. Patient OOP spending was calculated based on patients' direct payments to the hospital, which were recorded within the hospital cost accounting system (Horizon Performance Manager, McKesson Performance Analytics), as well as patient payments for neurosurgeon professional fees, recorded within the private practice billing system (Centricity Practice Solution version 12, GE Healthcare).

Data were aggregated in Microsoft Excel (version 14.2.5), and statistical analyses were performed using Stata/SE 15 (StataCorp.). Values are expressed as the mean \pm standard error, where appropriate, and statistical significance was established at $\alpha<0.05$. We created univariate and then multivariate mixed-effects linear regression models to evaluate the effect of each demographic and clinical variable on patient OOP spending. We used a mixed-effects model to account for the nested structure of our data, as highly specialized surgeons perform specific procedures at our institution. Extreme data were capped at the 99th percentile to reduce the effect of statistical outliers on the mean OOP spending in our univariate and multivariate analyses.

To examine changes in OOP spending over time, we created a generalized linear model with patient OOP payment as the primary outcome and year as a fixed effect. Our model controlled for case-mix differences over time by adjusting for the diagnosis-related group weights of each procedure. Partial fiscal periods for 2013 and 2016 were accounted for, as OOP payments were lower at the end of the year due to patients having met annual deductibles and OOP maximums. The postestimation margins command was used to obtain predicted OOP costs from our generalized linear model analysis. All payments were adjusted for inflation to reflect 2016 US dollar values (https://www.bls. gov/data/inflation_calculator.htm).

\section{Results}

Among the 6569 consecutive cranial neurosurgical procedures performed between 2013 and 2016 at our institution, craniotomy for tumor resection $(\mathrm{n}=2893 ; 44 \%)$ and CSF diversion procedures $(n=1096 ; 17 \%)$ were the most frequently performed (Table 1). Most patients presented with minor/moderate $(60 \%)$ SOI scores; only a small subset of patients was classified as undergoing emergency procedures $(n=471 ; 7 \%)$. The vast majority of treated patients were covered by commercial health insurance $(n=2724$; $42 \%)$ or had government-sponsored coverage $(n=3330$; 51\%). Patients were discharged to home in most cases (n $=4821 ; 73 \%$ ), while smaller subsets were discharged to a rehabilitation facility $(\mathrm{n}=779 ; 12 \%)$ or skilled nursing facility $(n=429 ; 7 \%)$.

Univariate analysis showed that the following patient factors were associated with higher OOP spending for cranial neurosurgical patients: younger age ( $<68$ years); craniotomies for pain, vascular lesion, or tumor, and endoscopic endonasal/intraventricular procedures for tumor; commercial insurance (vs Medicaid/Medicare/others/self-pay) and out-of-network plans; moderate SOI (vs minor); longer length of stay (2nd quartile vs 1st quartile) (all $\mathrm{p}<0.05$; Table 2). Our multivariate mixed-effects linear regression model confirmed that case categories (craniotomies for vascular lesion, pain, or tumor), commercial insurance, and out-of-network plans were independent predictors of higher patient OOP spending (all $\mathrm{p}<0.05$; Table 3 ).

We then examined patient OOP spending stratified by case categories. Craniotomy for pain (e.g., microvascular decompression) was associated with the highest patient OOP spending $(\$ 1151 \pm \$ 209)$, followed by endoscopic endonasal/intraventricular tumor resection $(\$ 834 \pm \$ 275$; Fig. 1). Hematoma evacuation and CSF diversion procedures were associated with the lowest patient OOP spending $(\$ 231 \pm \$ 33$ and $\$ 281 \pm \$ 54$, respectively). In a subgroup analysis, commercially insured patients, on average, contributed nearly twice as much as the overall population (Fig. 1). This disparity was starkest among deep brain stimulation implant procedures, where commercially insured patients paid over 3 times more OOP compared with all payers. 
TABLE 1. Patient characteristics for 6569 consecutive cranial neurosurgical cases from July 2013 to May 2016

\begin{tabular}{|c|c|}
\hline Variable & Value \\
\hline Mean age in yrs $( \pm S D)$ & $53.8 \pm 18.0$ \\
\hline \multicolumn{2}{|l|}{ Sex } \\
\hline Female & $3,368(48.7)$ \\
\hline Male & $3,201(51.3)$ \\
\hline \multicolumn{2}{|l|}{ Case category } \\
\hline Cranioplasty/wound revision/CSF leak repair & $361(5.5)$ \\
\hline Craniotomy for epilepsy & $51(0.8)$ \\
\hline Craniotomy for pain & $286(4.4)$ \\
\hline Craniotomy for tumor & $2,893(44.0)$ \\
\hline Craniotomy for vascular lesion & $549(8.4)$ \\
\hline CSF diversion & $1,096(16.7)$ \\
\hline DBS implant & $383(5.8)$ \\
\hline Endoscopic endonasal/intraventricular for tumor & $133(2.0)$ \\
\hline Hematoma evacuation & $550(8.4)$ \\
\hline Intracranial biopsy procedure & $267(4.1)$ \\
\hline Mean length of surgery in hrs ( \pm SD) & $3.0 \pm 2.0$ \\
\hline \multicolumn{2}{|l|}{ ASA class } \\
\hline I & $219(3.3)$ \\
\hline$\|$ & $1,697(25.8)$ \\
\hline III & $2,217(33.7)$ \\
\hline IV & $1,507(22.9)$ \\
\hline V & $929(14.1)$ \\
\hline \multicolumn{2}{|l|}{ Discharge } \\
\hline Home or self-care & $4,821(73.4)$ \\
\hline Rehabilitation facility & $779(11.9)$ \\
\hline Skilled nursing facility & $429(6.5)$ \\
\hline Other & $540(8.2)$ \\
\hline \multicolumn{2}{|l|}{ Insurance type } \\
\hline Commercial & $2,724(41.5)$ \\
\hline Medicaid & $914(13.9)$ \\
\hline Medicare & $2,416(36.8)$ \\
\hline Others & $350(5.3)$ \\
\hline Self-pay & $165(2.5)$ \\
\hline \multicolumn{2}{|l|}{ Insurance network } \\
\hline $\ln$ & $5,814(89.4)$ \\
\hline Out & $689(10.6)$ \\
\hline \multicolumn{2}{|l|}{ SOI } \\
\hline Minor & $1,916(29.2)$ \\
\hline Moderate & $2,217(33.8)$ \\
\hline Major & $1,507(22.9)$ \\
\hline Extreme & $929(14.1)$ \\
\hline \multicolumn{2}{|l|}{ Elective status } \\
\hline Elective & $6,098(92.8)$ \\
\hline Emergency & $471(7.2)$ \\
\hline
\end{tabular}

ASA = American Society of Anesthesiologists; DBS = deep brain stimulation. Values are presented as the number of patients (\%) unless stated otherwise.
TABLE 2. Univariate analysis of predictors of patient OOP spending for cranial neurosurgery cases

\begin{tabular}{|c|c|c|}
\hline Variable & Mean Cost \pm SE & $\mathrm{p}$ Value \\
\hline \multicolumn{3}{|l|}{ Age in yrs } \\
\hline Q1: $<42$ & $\$ 622 \pm 64$ & \\
\hline Q2: 42-56 & $\$ 746 \pm 59$ & 0.129 \\
\hline Q3: 57-67 & $\$ 760 \pm 73$ & 0.072 \\
\hline Q4: >67 & $\$ 263 \pm 32$ & $<0.001$ \\
\hline \multicolumn{3}{|l|}{ Sex } \\
\hline Male & $\$ 657 \pm 45$ & \\
\hline Female & $\$ 522 \pm 37$ & 0.053 \\
\hline \multicolumn{3}{|l|}{ Case category } \\
\hline Hematoma evacuation & $\$ 231 \pm 33$ & \\
\hline CSF diversion & $\$ 281 \pm 54$ & 0.743 \\
\hline $\begin{array}{l}\text { Cranioplasty/wound revision/CSF leak } \\
\text { repair }\end{array}$ & $\$ 300 \pm 90$ & 0.703 \\
\hline DBS implant & $\$ 347 \pm 44$ & 0.600 \\
\hline Craniotomy for epilepsy & $\$ 359 \pm 223$ & 0.831 \\
\hline Intracranial biopsy procedure & $\$ 404 \pm 74$ & 0.373 \\
\hline Craniotomy for vascular lesion & $\$ 673 \pm 102$ & 0.007 \\
\hline Craniotomy for tumor & $\$ 786 \pm 53$ & $<0.001$ \\
\hline $\begin{array}{l}\text { Endoscopic endonasal/intraventricular } \\
\text { for tumor }\end{array}$ & $\$ 834 \pm 275$ & 0.011 \\
\hline Craniotomy for pain & $\$ 1,151 \pm 209$ & $<0.001$ \\
\hline \multicolumn{3}{|l|}{ Insurance } \\
\hline Commercial & $\$ 1,083 \pm 60$ & \\
\hline Medicaid & $\$ 170 \pm 58$ & $<0.001$ \\
\hline Medicare & $\$ 263 \pm 30$ & $<0.001$ \\
\hline Others & $\$ 341 \pm 116$ & $<0.001$ \\
\hline Self-pay & $\$ 185 \pm 76$ & $<0.001$ \\
\hline \multicolumn{3}{|l|}{ Insurance network } \\
\hline $\ln$ & $\$ 547 \pm 27$ & \\
\hline Out & $\$ 968 \pm 156$ & $<0.001$ \\
\hline \multicolumn{3}{|l|}{ SOl } \\
\hline Minor & $\$ 707 \pm 55$ & 0.015 \\
\hline Moderate & $\$ 638 \pm 54$ & 0.089 \\
\hline Major & $\$ 472 \pm 55$ & 0.422 \\
\hline Extreme & $\$ 436 \pm 77$ & 0.531 \\
\hline \multicolumn{3}{|l|}{ Length of stay in days } \\
\hline Q1: $<2$ & $\$ 514 \pm 48$ & \\
\hline Q2: 2-3 & $\$ 852 \pm 67$ & $<0.001$ \\
\hline Q3: 4-7 & $\$ 555 \pm 53$ & 0.731 \\
\hline Q4: >7 & $\$ 363 \pm 50$ & 0.114 \\
\hline \multicolumn{3}{|l|}{ Elective status } \\
\hline Elective & $\$ 604 \pm 30$ & \\
\hline Emergency & $\$ 421 \pm 126$ & 0.207 \\
\hline
\end{tabular}

$Q=$ quartile

Boldface type indicates statistical significance. 
TABLE 3. Multivariate analysis of predictors of patient OOP spending for cranial neurosurgery cases

\begin{tabular}{|c|c|c|}
\hline Variable & Estimate & p Value \\
\hline Age (10-yr increments) & $\$ 30$ & 0.214 \\
\hline Sex (male vs female) ${ }^{*}$ & $\$-39$ & 0.512 \\
\hline \multicolumn{3}{|l|}{ Case category (vs hematoma evacuation) } \\
\hline CSF diversion & $\$-19$ & 0.890 \\
\hline Cranioplasty/wound revision/CSF leak repair & $\$-35$ & 0.834 \\
\hline DBS implant & $\$-32$ & 0.858 \\
\hline Craniotomy for epilepsy & $\$ 68$ & 0.847 \\
\hline Intracranial biopsy procedure & $\$ 20$ & 0.915 \\
\hline Craniotomy for vascular lesion & $\$ 293$ & 0.049 \\
\hline Craniotomy for tumor & $\$ 295$ & 0.018 \\
\hline Endoscopic endonasal/intraventricular for tumor & $\$ 370$ & 0.118 \\
\hline Craniotomy for pain & $\$ 511$ & 0.006 \\
\hline \multicolumn{3}{|l|}{ Insurance (vs commercial) } \\
\hline Medicaid & $\$-909$ & $<0.001$ \\
\hline Medicare & $\$-781$ & $<0.001$ \\
\hline Others & $\$-1,045$ & $<0.001$ \\
\hline Self-pay & $\$-752$ & $<0.001$ \\
\hline Insurance network (in vs out)* & $\$ 738$ & $<0.001$ \\
\hline \multicolumn{3}{|l|}{ SOI (vs minor) } \\
\hline Moderate & $\$ 54$ & 0.755 \\
\hline Major & $\$-4$ & 0.981 \\
\hline Extreme & $\$ 97$ & 0.615 \\
\hline \multicolumn{3}{|l|}{ Length of stay in days (vs Q1: <2) } \\
\hline Q2: 2-3 & $\$ 122$ & 0.211 \\
\hline Q3: 4-7 & $\$-61$ & 0.560 \\
\hline Q4: >7 & $\$-157$ & 0.176 \\
\hline Elective status (elective vs emergency)* & $\$ 143$ & 0.268 \\
\hline
\end{tabular}

Boldface type indicates statistical significance.

* Parenthetical categories are listed as (reference category vs effect).

Lastly, we examined the temporal trend in OOP spending from 2013 to 2016 (Fig. 2). Patient OOP payment estimates were adjusted for inflation, case-mix differences, and partial fiscal periods in our data collection. The cumulative rate of growth in individual patient OOP spending was 17\%, from \$598 in 2013 to \$698 in 2016. Commercially insured patients saw more substantial increases in spending each year, with an average annual growth rate of $13 \%$. The cumulative rate of growth for commercially insured patients was $42 \%$, from $\$ 991$ in 2013 to $\$ 1403$ in 2016 , which was statistically significant ( $<<0.001)$.

\section{Discussion}

With changes to the health insurance market, patients are becoming increasingly responsible for a higher share of their health care costs in the forms of deductibles, coinsurance, and out-of-network charges. . $^{16,20,23,26}$ Our data demonstrate that for cranial neurosurgical procedures, patient OOP spending is significant and is rising at a rate that exceeds the rate of inflation and economic growth. These findings may have important implications for neurosurgical providers and policy makers, and this analysis represents a step toward improved cost transparency in neurosurgery.

Proponents of increased patient cost sharing argue that shifting a greater proportion of health care costs onto the consumer can help reduce unnecessary care and contain overall health expenditures. ${ }^{14,24}$ However, increased OOP cost can impede access to care and negatively affect a patient's quality of life. A recent study showed that patients burdened by high OOP costs are likely to drop health insurance coverage, reduce their spending on other necessities such as food and clothing, or take prescribed medication less frequently. ${ }^{27}$ In fact, $22 \%$ of Americans skipped medical consultations and $18 \%$ did not purchase prescribed medicine due to cost in $2016 .{ }^{15}$ Additionally, access problems disproportionately afflict patients from low socioeconomic strata, ${ }^{6,21,23,25}$ with $43 \%$ of low-income adults reporting unmet medical needs due to the costs of care..$^{15}$

Despite the growing issue of patient cost sharing, very few studies address patient OOP cost issues in surgical specialties. A comprehensive PubMed search examining patient payments, OOP costs, and cost sharing in the surgical literature resulted in 61 articles. After screening the title and abstract, 53 articles were excluded for various reasons (e.g., without cost data, nonsurgical literature, offtopic). In our review of the literature, 8 articles examined OOP spending in surgery (obstetrics and gynecology, 3,18 , ${ }^{19,22}$ ophthalmology, ${ }^{17}$ transplant, ${ }^{18}$ orthopedics, ${ }^{10}$ plastic surgery, ${ }^{2}$ and general surgery $\left.{ }^{1}\right)$; however, none of the studies examined neurosurgical care. Four of these studies were conducted internationally, 3,17,18,22 and 1 study was based on a survey of patients, ${ }^{19}$ which is prone to patient recall bias and underreporting of costs. Two studies ${ }^{2,10}$ that explored OOP costs in pediatric orofacial clefts and total hip arthroplasty included fewer than 50 patients, making extrapolation and generalizability of analysis challenging. Finally, one study examined OOP spending for hospitalization of 7 common inpatient procedures, including spinal fusion, using a national database. ${ }^{1}$ The study authors found that total cost sharing increased 37\% from 2009 to 2013 after controlling for inflation and case-mix differences. However, this study only analyzed medical claims from commercially insured patients.

In our multivariate analyses of 6569 consecutive cranial neurosurgical cases of all payer types, we found that case categories (craniotomy for pain, tumor, and vascular lesions), commercial insurance, and out-of-network plans were significantly associated with higher patient OOP spending. Craniotomy for microvascular decompression, for example, was associated with a 5 times higher mean OOP payment when compared with ventriculoperitoneal shunt insertion. This large variation in costs among case categories highlights the importance of financial considerations by patients and providers prior to surgery, as some elective procedures may be associated with significant patient financial burden. At our institution, we recommend providers use this information to improve patient-physician communication about potential health care costs, and we offer patient financial counseling services to help patients better anticipate their fiscal responsibilities.

Another important finding of our study is the significant growth of OOP spending over time, which was most pro- 


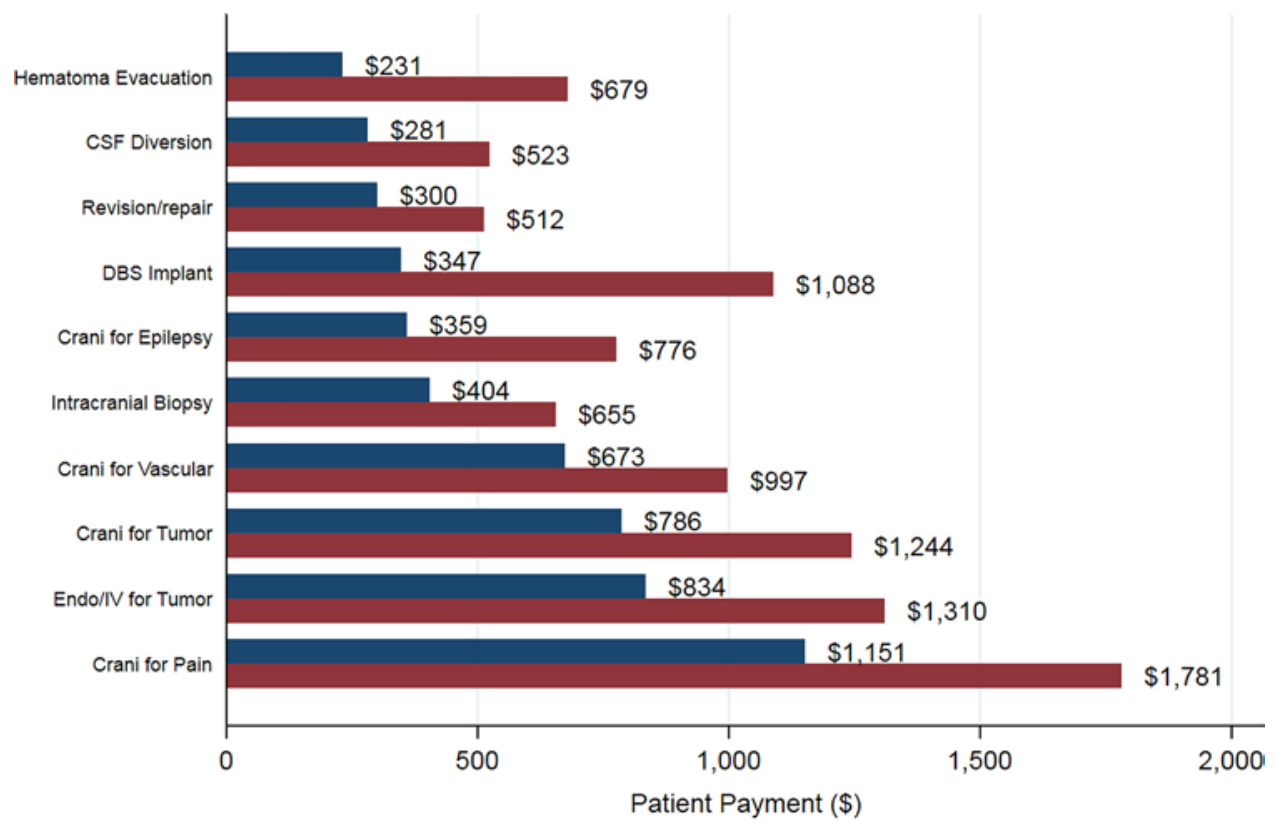

FIG. 1. All patients (b/ue) and commercially insured patients (red) OOP spending by case category. Crani = craniotomy; Endo/IV = endoscopic endonasal/intraventricular; DBS = deep brain stimulation.

nounced for commercially insured patients. After controlling for inflation, the cumulative rate of growth for commercially insured patients was $42 \%$ in our study period, which exceeded \$1400 for average OOP payments in 2016. Additionally, as health care costs continue to rise, provider networks have grown smaller, leading consumers to seek out-of-network care. ${ }^{20}$ "Narrow networks," insurance plans that include a small group of contracted physicians in the area, have grown popular in recent years due to lower premiums and the individual mandate; however, OOP costs for patients in these narrow networks could be significant. ${ }^{8}$ Our analysis supports these findings, as out-of-network coverage was independently associated with increased patient OOP spending in our multivariate model. In our evolving health care environment, with discussion of new legislative changes to health insurance plans, our findings warrant greater attention from policy makers seeking to provide affordable and accessible care networks to surgical patients.

Although our analysis represents a large cohort of patients undergoing a variety of cranial neurosurgery procedures, it is limited by its retrospective nature and singleinstitution study design. Treatments in all cases were performed at a single, highly specialized, tertiary referral center for neurosurgical procedures, and our work may not be representative of neurosurgical cases nationally, as there is known geographic variation in costs. ${ }^{13,28}$ Additionally, our study population has an underrepresentation of commercially insured patients (42\%), compared with national averages of $68 \%,{ }^{4}$ and an overrepresentation of Medicare patients (37\%). The smaller proportion of commercially insured patients, who have high mean OOP spending as suggested by our data, likely lowers our mean OOP cost estimates. Despite these limitations, our examination of patient OOP spending represents the largest analysis of neurosurgical procedures to date. Future investigations focused on patient OOP spending on a national scale are warranted.

\section{Conclusions}

Patient OOP spending for cranial neurosurgical procedures is significant and increased from 2013 to 2016 in our cohort of patients. Independent drivers of patient OOP spending included commercial insurance coverage, out-ofnetwork care, and specific case categories, including craniotomy for pain, vascular lesion, and tumor, among others. As health care costs continue to rise and patient cost sharing becomes more prevalent, the potential financial burden of neurosurgical care should be considered by patients, providers, and policymakers.

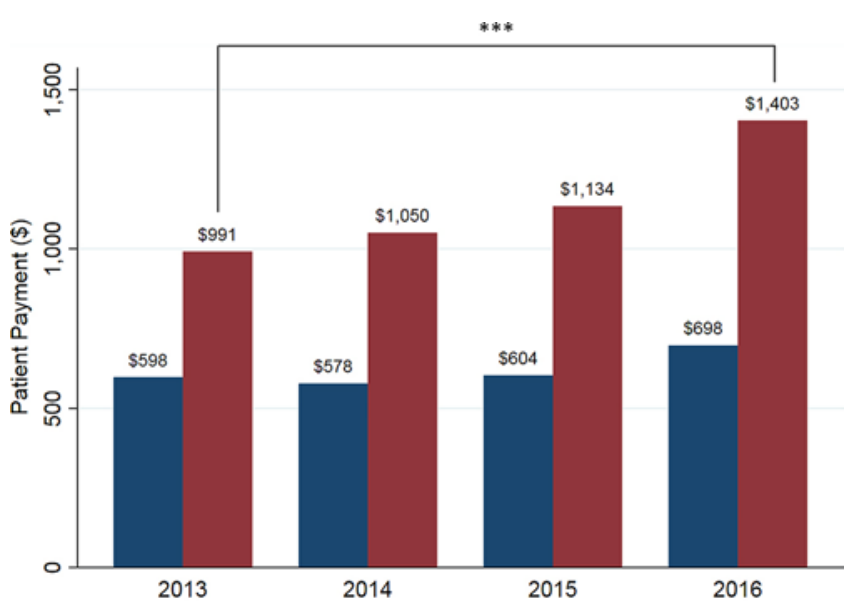

FIG. 2. Patient OOP spending for all patients (blue) and commercially insured patients (red) who underwent cranial neurosurgery between 2013 and 2016. All payments are adjusted for inflation to reflect 2016 US dollar values. ${ }^{* *} p<0.001$. 


\section{Acknowledgments}

We thank Julie Eichacker, Tiffany Blaine, Pamela BautistaAndrone, Cynthia Stark, Brian Dobyns, and Sibylle Freiwald for their assistance with cost data acquisition.

\section{References}

1. Adrion ER, Ryan AM, Seltzer AC, Chen LM, Ayanian JZ, Nallamothu BK: Out-of-pocket spending for hospitalizations among nonelderly adults. JAMA Intern Med 176:13251332,2016

2. Albino FP, Koltz PF, Girotto JA: Predicting out-of-pocket costs in the surgical management of orofacial clefts. Plast Reconstr Surg 126:188e-189e, 2010

3. Anderson GA, Ilcisin L, Kayima P, Abesiga L, Portal Benitez $\mathrm{N}$, Ngonzi J, et al: Out-of-pocket payment for surgery in Uganda: The rate of impoverishing and catastrophic expenditure at a government hospital. PLoS One 12:e0187293, 2017

4. Barnett JC, Berchick ER: Health Insurance Coverage in the United States: 2016. Washington, DC: U.S. Census Bureau, 2017

5. Centers for Medicare and Medicaid Services: National health expenditure 2016 highlights. CMS.gov. (https://www. cms.gov/Research-Statistics-Data-and-Systems/StatisticsTrends-and-Reports/NationalHealthExpendData/downloads/ highlights.pdf) [Accessed March 5, 2018]

6. Chernew M, Gibson TB, Yu-Isenberg K, Sokol MC, Rosen $\mathrm{AB}$, Fendrick AM: Effects of increased patient cost sharing on socioeconomic disparities in health care. J Gen Intern Med 23:1131-1136, 2008

7. Donelan K, Blendon RJ, Schoen C, Davis K, Binns K: The cost of health system change: public discontent in five nations. Health Aff (Millwood) 18:206-216, 1999

8. Gillen EM, Hassmiller Lich K, Trantham LC, Weinberger M, Silberman P, Holmes M: The effect of narrow network plans on out-of-pocket cost. Am J Manag Care 23:540-545, 2017

9. Hamel L, Norton M, Pollitz K, Levitt L, Claxton G, Mollyann B: The Burden of Medical Debt: Results from the Kaiser Family Foundation/New York Times Medical Bills Survey. Menlo Park: Kaiser Family Foundation, 2016 (https://www.kff.org/health-costs/report/the-burden-ofmedical-debt-results-from-the-kaiser-family-foundationnewyork-times-medical-bills-survey/) [Accessed March 5, 2018]

10. Heiner DE, Mauerhan DR, Masonis JL, Heath J: Patient outof-pocket expenses in major orthopedic procedures: total hip arthroplasty as a case study. J Arthroplasty 23:509-514, 2008

11. Himmelstein DU, Thorne D, Warren E, Woolhandler S: Medical bankruptcy in the United States, 2007: results of a national study. Am J Med 122:741-746, 2009

12. Keehan SP, Stone DA, Poisal JA, Cuckler GA, Sisko AM, Smith SD, et al: National health expenditure projections, 2016-25: price increases, aging push sector to 20 percent of economy. Health Aff (Millwood) 36:553-563, 2017

13. Liu CY, Zygourakis CC, Yoon S, Kliot T, Moriates C, Ratliff $\mathrm{J}$, et al: Trends in utilization and cost of cervical spine surgery using the National Inpatient Sample Database, 2001 to 2013. Spine (Phila Pa 1976) 42:E906-E913, 2017

14. Manning WG, Newhouse JP, Duan N, Keeler EB, Leibowitz A, Marquis MS: Health insurance and the demand for medical care: evidence from a randomized experiment. Am Econ Rev 77:251-277, 1987

15. Organisation for Economic Co-operation and Development: Health at a Glance 2017. OECD Indicators. Paris: OECD Publishing, 2017 (https://www.keepeek.com//Digital-AssetManagement/oecd/social-issues-migration-health/healthat-a-glance-2017_health_glance-2017-en\#page4) [Accessed March 5, 2018]

16. Paez KA, Zhao L, Hwang W: Rising out-of-pocket spending for chronic conditions: a ten-year trend. Health Aff (Millwood) 28:15-25, 2009

17. Perera C, De Silva D, Perera LR: Estimation of provider cost and the out of pocket expenditure for cataract surgery at a base hospital. Ceylon Med J 61:200, 2016

18. Ramachandran R, Jha V: Kidney transplantation is associated with catastrophic out of pocket expenditure in India. PLoS One 8:e67812, 2013

19. Roberts SC, Gould H, Kimport K, Weitz TA, Foster DG: Out-of-pocket costs and insurance coverage for abortion in the United States. Womens Health Issues 24:e211-e218, 2014

20. Robinson JC: Renewed emphasis on consumer cost sharing in health insurance benefit design. Health Aff (Millwood) Suppl Web Exclusives:W139-W154, 2002

21. Tamblyn R, Laprise R, Hanley JA, Abrahamowicz M, Scott $\mathrm{S}$, Mayo N, et al: Adverse events associated with prescription drug cost-sharing among poor and elderly persons. JAMA 285:421-429, 2001

22. Tchuenche M, Haté V, McPherson D, Palmer E, Thambinayagam A, Loykissoonlal D, et al: Estimating client out-of-pocket costs for accessing voluntary medical male circumcision in South Africa. PLoS One 11:e0164147, 2016

23. Trivedi AN, Moloo H, Mor V: Increased ambulatory care copayments and hospitalizations among the elderly. N Engl J Med 362:320-328, 2010

24. Wharam JF, Landon BE, Galbraith AA, Kleinman KP, Soumerai SB, Ross-Degnan D: Emergency department use and subsequent hospitalizations among members of a highdeductible health plan. JAMA 297:1093-1102, 2007

25. Wharam JF, Zhang F, Landon BE, Soumerai SB, Ross-Degnan D: Low-socioeconomic-status enrollees in high-deductible plans reduced high-severity emergency care. Health Aff (Millwood) 32:1398-1406, 2013

26. Wholey D, Feldman R, Christianson JB: The effect of market structure on HMO premiums. J Health Econ 14:81-105, 1995

27. Zafar SY, Peppercorn JM, Schrag D, Taylor DH, Goetzinger AM, Zhong X, et al: The financial toxicity of cancer treatment: a pilot study assessing out-of-pocket expenses and the insured cancer patient's experience. Oncologist 18:381-390, 2013

28. Zygourakis CC, Liu CY, Yoon S, Moriates C, Boscardin C, Dudley RA, et al: Analysis of cost variation in craniotomy for tumor using 2 national databases. Neurosurgery 81:972979,2017

\section{Disclosures}

Dr. Little: ownership in Kogent and Spiway.

\section{Author Contributions}

Conception and design: Lawton, Yoon, Mooney. Acquisition of data: Yoon, Mooney, Bohl, Sheehy. Analysis and interpretation of data: Yoon, Mooney. Drafting the article: Yoon, Mooney. Critically revising the article: all authors. Reviewed submitted version of manuscript: all authors. Statistical analysis: Yoon. Study supervision: Lawton, Nakaji, Little.

\section{Supplemental Information Videos}

Video Abstract. https://vimeo.com/263549642.

\section{Correspondence}

Michael T. Lawton: Barrow Neurological Institute, Phoenix, AZ. michael.lawton@barrowbrainandspine.com. 